\title{
Timing of allergy-preventive and immunomodulatory dietary interventions: are prenatal, perinatal or postnatal strategies optimal?
}

\author{
Maria Jenmalm and Karel Duchén
}

\section{Linköping University Post Print}

\section{Tweet}

N.B.: When citing this work, cite the original article.

This is the pre-reviewed version of the following article:

Maria Jenmalm and Karel Duchén, Timing of allergy-preventive and immunomodulatory dietary interventions: are prenatal, perinatal or postnatal strategies optimal?, 2013, Clinical and Experimental Allergy, (43), 3, 273-278.

which has been published in final form at:

http://dx.doi.org/10.1111/cea.12003

Copyright: Wiley-Blackwell http://eu.wiley.com/WileyCDA/Brand/id-35.html

Postprint available at: Linköping University Electronic Press http://urn.kb.se/resolve?urn=urn:nbn:se:liu:diva-90064 


\title{
Timing of allergy preventive and immunomodulatory dietary interventions -
} are prenatal, perinatal or postnatal strategies optimal?

\author{
Maria C Jenmalm, $\mathrm{PhD}^{1}$ \\ Karel Duchén, $\mathrm{MD}, \mathrm{PhD}^{2}$
}

Division of Inflammation Medicine ${ }^{1}$ and Paediatrics ${ }^{2}$, Department of Clinical and Experimental Medicine, Linköping University, SE-581 85 Linköping, Sweden

Correspondence to: Maria Jenmalm, PhD, Professor

Dept of Clin \& Experimental Medicine / AIR pl 10

Faculty of Health Sciences, Linköping University

SE-581 85 Linköping

Sweden

Phone: +46-10-103 4101

Fax: +46-13-13 2257

E-mail: maria.jenmalm@liu.se 


\begin{abstract}
The increasing allergy prevalence in affluent countries may be caused by reduced microbial stimulation and a decreased dietary $\omega-3 / \omega-6$ long chain polyunsaturated fatty acid (LCPUFA) ratio, resulting in an abnormal postnatal immune maturation. The timing of allergy preventive probiotic and $\omega-3$ LCPUFA interventions is critical, as early life events occurring during critical windows of immune vulnerability can have long-term impact on immune development. The maternal dietary and microbial environment during pregnancy may program the immune development of the child. Prenatal environmental exposures may alter gene expression via epigenetic mechanisms, aiming to induce physiological adaptations to the anticipated postnatal environment, but potentially also increasing disease susceptibility in the offspring if exposures are mismatched. Although the importance of fetal programming mostly has been studied in cardiovascular and metabolic disease, this hypothesis is also very attractive in the context of environmentally influenced immune-mediated diseases. This review focuses on how prenatal, perinatal or postnatal $\omega-3$ LCPUFA interventions regulate childhood immune and allergy development and if synergistic effects may be obtained by simultaneous probiotic supplementation. We propose that combined pre- and postnatal preventive measures may be most efficacious. Increasing knowledge on the immunomodulatory effects of prenatal, perinatal and postnatal interventions, will help to direct future strategies to combat the allergy epidemic.
\end{abstract}

Key words: $\quad$ allergy, atopy, childhood, prevention, $\omega-3$ long chain polyunsaturated fatty acids, probiotics, immune regulation, cytokines, epigenetics, pregnancy 


\section{Introduction}

The allergy epidemic in affluent countries must be counteracted by research identifying successful preventive measures. Supplementation of allergy protective factors that may have been lost in countries with a Western lifestyle, such as microbial stimulation with probiotics [1-8] and $\omega-3$ long chain polyunsaturated fatty acids (LCPUFA) to redress the decreased dietary $\omega-3 / \omega-6$ LCPUFA ratio [8-16], are currently evaluated in allergy intervention trials. The timing of such interventions is critical, as early life events occurring during critical windows of immune vulnerability can have long-term impact on immune development $[7,8,17]$. Factors influencing the early education and maturation of the immune system are thus especially important for subsequent allergy development $[7,8,17,18]$.

\section{Immunomodulatory effects of pre- and perinatal supplementation with $\omega-3$}

\section{LCPUFA}

In order to develop efficacious preventive measures, it is crucial to understand the underlying immunological mechanisms and how infant immune responses are affected by the interventions. Increasing the dietary $\omega-3 / \omega-6$ LCPUFA ratio may have anti-inflammatory effects [19]. Thus, the $\omega-6$ polyunsaturated fatty acid arachidonic acid gives rise to eicosanoids including prostaglandin $\mathrm{D}_{2}$, prostaglandin $E_{2}$ and leukotriene $B_{4}$, with significantly higher inflammatory potential than the $\omega-3$ derived 3-series prostaglandins and 5-series leukotrienes [19]. Furthermore, a low $\omega$ 3 LCPUFA intake may be associated with decreased formation of n-3 derived resolvins and protectins, which reduce and actively resolve inflammation in animal models [20], although their anti-inflammatory potential in humans is not yet well studied [19]. Supporting the theory of infant immunomodulatory effects of $\omega-3$ fatty acids, supplementation with $\omega-3$ LCPUFA rich fish oil during pregnancy resulted in lower cord blood levels of the Th2 cytokines IL-4 [21] and IL-13 [21, 22]. Furthermore, we have found that fish oil supplementation during pregnancy and lactation resulted in lower ratios of the Th2-associated chemokine CCL17 to the Th1-associated chemokine CXCL11 in the circulation of infants without, but not with, maternal 
history of allergy, as well as increased IgG titers to diphtheria and tetanus toxins after vaccination in nonallergic, but not allergic, infants [23]. Also, fish oil supplementation in allergic women during pregnancy was associated with a higher percentage of cord blood CD34+ hemopoietic progenitor cells and more IL-5 responsive eosinophil/basophil colony forming units [24], as well as reduced neutrophil LTB4 production in neonates [25].

\section{Immunomodulatory effects of postnatal supplementation with $\omega-3$ LCPUFA}

In contrast to pre- and perinatal interventions, the effects of $\omega-3$ LCPUFA supplementation during infancy on development of T-cell and innate immunity have not been studied previously. Such studies can help shed light on the issue of the optimal timing of allergy preventive interventions. In a recent article of this journal, D'Vaz and colleagues describe the immunomodulatory effects of $650 \mathrm{mg}$ daily fish oil (280 mg docosahexaenoic acid (DHA) and $110 \mathrm{mg}$ eicosapentanoic acid (EPA)) supplementation from birth to six months of age in 150 infants of allergic mothers in a placebo-controlled randomised study [26]. The infants were part of a larger $(n=420)$ study population but were representative of the main trial regarding maternal and paternal age, parity, gestation, birth weight and length, head circumference, household pets gender, delivery mode and season of birth. Direct supplementation, squeezing the content of the fish oil capsules into the mouth of the infant or adding it to milk with the first daily feed, was associated with some difficulty and blinding could not be perfectly achieved, due to the fish oil smell. Postnatal fish oil supplementation did result in higher plasma levels of the $\omega-3$ LCPUFA DHA and EPA and reduced erythrocyte $\omega-6$ arachidonic acid (AA) levels compared with placebo. In agreement with the author's hypothesis that the supplementation would decrease infant allergy-associated Th2 responsiveness, lower levels of the Th2 cytokine IL-13 was observed in the active than in the placebo group at six months of age after stimulation of peripheral blood mononuclear cells with house dust mite allergen, while the PHA mitogen-induced levels of the Th1 cytokine IFN- $\gamma$ and the proinflammatory cytokine TNF were increased. Furthermore, high plasma DHA levels were associated with low responses of the Th2 cytokines IL-5 
and IL-13 after stimulation with the cow's milk allergen $\beta$-lactoglobulin. In contrast to the author's hypothesis, the supplementation did not affect IFN- $\gamma$-induced HLADR expression on monocytes or the numbers of CD4+CD25hiCD127lo regulatory $\mathrm{T}$ cells and their Foxp3 expression. Data from flow cytometry analyses were only available from 21 infants, however, limiting the power of these analyses.

\section{Allergy preventive effects of prenatal, perinatal or postnatal intervention strategies}

Although the effect of postnatal fish oil supplementation on development of eczema should be evaluated for the main cohort of 420 children, the prevalence of eczema at 6 and 12 months of age in the study by D'Vaz et al did not differ between the supplementation groups among these 150 children, despite the decreased Th2 responsiveness to allergens [26]. Other studies on postnatal fish oil supplementation, given directly to the infants $[10,12,27,28]$ or to the lactating mothers [11], have not demonstrated allergy preventive benefits. In contrast, administration of fish oil to mothers during pregnancy $[9,13,16,28,29]$ or during pregnancy and lactation [14, 15] has shown promising allergy preventive effects. Also, a preventive effect of probiotics on atopic eczema has primarily been demonstrated in studies by us and others where probiotics were given both pre- and postnatally [1-3, 7], whereas studies with postnatal or prenatal supplementation only failed to prevent allergic disease [4-6]. Prenatal probiotic supplementation was not given until 36 weeks of gestation in any of the studies, however [1-3, 6, 7]. If prenatal microbial exposure is vital for the preventive effect, as also suggested by epidemiological [30-32] and experimental $[33,34]$ studies, probiotic supplementation should maybe be started already from the second trimester of pregnancy, when circulating fetal $\mathrm{T}$ cells have developed $[7,8]$. In summary, findings from both probiotic and $\omega-3$ supplementation studies support the concept that maternally mediated signals during perinatal critical windows of immune vulnerability may affect immune development in the offspring.

\section{Dosage of $\omega-3$ LCPUFA supplementation and allergy prevention}


In addition to the timing of intervention, the dosage is also critically important. Which dose of $\omega-3$ LCPUFA that is required at various times of dietary interventions to achieve a favourable $\omega-3 / \omega-6$ LCPUFA ratio in maternal milk and infant serum phospholipids [35] is not understood. With a dosage of $650 \mathrm{mg}$ fish oil daily supplementation, D'Vaz et al clearly influenced the composition of plasma an erythrocyte phospholipids towards a higher $\omega-3 / \omega-6$ ratio [26]. Although they actually found a positive relationship between a higher EPA/AA ratio in erythrocyte membranes and eczema in the infants, they were not able to demonstrate that the $\omega-3$ PUFA supplementation prevented eczema in this subpopulation of the main cohort at 12 months of age [26]. Similarly, in a previous postnatal intervention study [36], infants with heredity for bronchial asthma were supplemented with $500 \mathrm{mg}$ fish oil (180 mg $\omega$-3 LCPUFA) from 6 months of age, while at the same time, the study promoted the increased use of $\omega-3$ LCPUFA in the household as compared to the children randomized to the placebo group. Increased plasma levels of $\omega-3$ LCPUFA were reported in the intervention group at 18 months, 3 and 5 years of age $[10,12,27$, 36]. Neither any relationship between $\omega-3$ PUFA plasma levels and allergic disease, nor any preventive effect of the $\omega$-3 PUFA supplementations was shown at any time, however $[10,12,27,37]$. The amount of $\omega$-3 LCPUFA supplements used during pregnancy has been substantially higher. Dosages between 1.5 to $4.5 \mathrm{~g}$ of fish oil, corresponding to $0.9 \mathrm{~g}$ [16], $1.4 \mathrm{~g}$ [13], $2.7 \mathrm{~g}$ [14] and $3.1 \mathrm{~g}$ [9] EPA and DHA, in the intervention group during pregnancy have been shown to substantially change maternal plasma $\omega-3 / \omega-6$ LCPUFA ratio and show promising allergy preventive effects. Particularly the maternal plasma $\omega-3$ LCPUFA levels at birth seem to be an important marker for the development of allergic disease, as the frequency of $\operatorname{IgE}$ associated disease at two years of life was reported to decrease with increasing DHA levels in maternal plasma [15]. These dose-related findings clearly need to be further addressed in relation to appropriate timing of interventions in future studies.

\section{Maternal atopy and allergy preventive strategies}

As the study by D'Vaz and colleagues included allergic mothers only, the influence of maternal atopic heredity on the effect of postnatal fish oil supplementation on 
immune and eczema development could not be determined [26]. Interestingly, while the allergy preventive and immunomodulatory effects in our study of maternal fish oil supplementation during pregnancy and lactation seemed to be strongest in infants of non-atopic mothers $[15,23]$, the preventive effects in our probiotic study were more pronounced in children of atopic mothers where Lactobacillus reuteri was administered to mothers from gestational week 36 and to infants during the first year of life [3]. An enhanced effect of maternal and infant probiotic supplementation in children of atopic mothers could suggest that modulatory influences on perinatal immune-mediated signals are particularly important in the presence of maternal allergic inflammation [7]. The more pronounced preventive effect of $\omega-3$ supplementation in non-atopic than atopic mothers on infant allergy development [15] and Th1/Th2 balance [23] could be due to a disturbed polyunsaturated fatty acid metabolism in atopic individuals [38]. As the effects of probiotic and fish oil supplementation seem to vary by maternal atopic status, a combined perinatal supplementation strategy may be more successful. Furthermore, probiotic and $\omega-3$ polyunsaturated fatty acid administration may act synergistically at the cellular level, via immunoregulatory [7] and anti-inflammatory [19] mechanisms, respectively. We are now testing these possible synergistic effects in a new double blind placebo controlled randomized study, PROOM-3, recruiting pregnant women from February 2012 onwards (for details please see ClinicalTrials.gov Identifier NCT01542970). Pregnant mothers $(n=480)$ from high-risk families will be included in the study at the $20^{\text {th }}$ week of gestation. They will be randomized to 4 study groups. One group will receive placebo for $\omega-3$ and $L$ reuteri, the second will receive $\omega-3$ supplementation and placebo regarding $L$ reuteri, the third will receive $L$ reuteri and placebo regarding $\omega-3$ and the fourth group will receive both $\omega-3$ and L reuteri supplementation. $\omega-3$ capsules will be given to mothers during pregnancy and lactation while $L$ reuteri oil drops will be given to the mothers during pregnancy and to the children during the first year of life. The children will then be followed to two years of age, the primary outcome being IgE-associated eczema and secondary outcomes will include maternal and infant immunomodulation. Thus, in this study the effect of longer exposure to probiotics during pregnancy and postnatally on allergy prevention can be evaluated, as well as synergistic effects between probiotics and $\omega-3$ supplementation. 
Furthermore, the allergy preventive effect of perinatal $\omega-3$ supplementation described in our study by Furuhjelm et al $[14,15]$ may be confirmed by another independent study. Safety is of course of outmost concern in any studies evaluating perinatal treatment studies. Probiotic and $\omega-3$ supplementation studies during pregnancy, including studies on prevention of preterm delivery, have previously been well tolerated, with low risks for side effects [15, 39-41]. A recent systematic review concluded that $\omega-3$ LCPUFA supplementation during pregnancy resulted in a modest increase in birthweight, a lower risk of early preterm delivery and that occurrence of side effects was generally similar except for belching and bad taste, occurring more frequently in the n-3 LCPUFA-supplemented than the placebo groups [41].

\section{Epigenetic regulation and prenatal allergy prevention}

Environmental exposures during pregnancy may alter gene expression in the offspring via epigenetic mechanisms, heritable changes in gene expression occurring without alterations in the DNA sequences [42], a kind of cellular memory. Epigenetic modifications determine the degree of DNA compaction and accessibility for gene transcription, thus resulting in changes in gene expression that are subsequently passed to somatic daughter cells during mitosis [42]. The main processes modulating DNA accessibility to establish epigenetic memory occur via posttranslational histone modifications and methylation of DNA CpG dinucleotides [42]. DNA methylation, associated with transcriptional repression, is more rigid than histone modifications, with DNA methyltransferases conferring covalent methyl modifications to evolutionary conserved regulatory gene elements, $\mathrm{CpG}$ islands [42]. The methylation pattern is thus preserved with high fidelity through cell divisions, assuring preservation of cellular inheritance [42].

Prenatal environmental exposures may alter gene expression via epigenetic mechanisms, aiming to induce physiological adaptations to the anticipated postnatal environment, but potentially also increasing offspring disease susceptibility [43]. This "Developmental Origins of Health and Disease" hypothesis [43] was originally 
proposed by David Barker [44]. Although the importance of fetal programming mostly has been studied in cardiovascular and metabolic disease [43], this hypothesis is also very attractive in the context of environmentally influenced immune-mediated diseases. Developmental plasticity may attempt to match the responses of the offspring to the environment predicted to be experienced via epigenetic mechanisms, but when the responses are mismatched, disease risk may increase [45]. Possibly, interventions that are given both pre- and postnatally may decrease the risk for mismatched responses (Fig). The maternal dietary and microbial environment during pregnancy may program the immune development of the child [17], via epigenetic mechanisms, regulating appropriate maturation of innate immunity [30,33] and T helper and regulatory responses [46-48]. Th1, Th2 and Th17 differentiation is under epigenetic control and human $\mathrm{T}$ regulatory cell commitment requires demethylation of the FOXP3 promoter [49].

Epigenetically regulated childhood immune development by maternal dietary and microbial exposure is likely induced via changes in maternal immune regulation [33, 50], as there is a close immunological interaction between the mother and her offspring during pregnancy $[7,8,51]$. The placenta allows a cross-talk between maternal stimuli, possibly induced via microbial stimulation of maternal Toll-like receptors, and fetal responses [33]. As fetal $\mathrm{T}$ cells have developed during the second trimester of gestation, maternal signals may then direct the immune cell lineage commitment of the offspring during a critical developmental period when the epigenetic program is highly susceptible to environmental influences [17]. During pregnancy, the fetal-maternal interface is characterized by high levels of Th2-like cytokines and enrichment of $T$ regulatory cells, diverting the maternal immune response away from damaging Th1-mediated immunity [7]. The association of cord blood IgE levels and neonatal IFN- $\gamma$ production with maternal but not paternal atopic heredity may depend on an even stronger Th2-deviation in atopic than nonatopic pregnant women $[7,52,53]$. As the cytokine milieu shapes the Thelper differentiation, particularly during naïve as compared to established responses [54], the neonatal immune system is Th2-skewed $[7,55]$. We have shown an even more marked neonatal Th2-skewing in infants later developing allergic disease [51, 55, 56], 
possibly due to prenatal epigenetic effects via maternal immune regulation that may be possible to redress by increasing the dietary $\omega-3 / \omega-6$ LCPUFA ratio or by enhanced microbial exposure, e $g$ via fish oil or probiotic supplementation, during and after pregnancy [8]. The Th2-bias of the new-born should then develop toward a more balanced immune phenotype, including maturation of Th1-like responses [47] and appropriate development of regulatory $\mathrm{T}$ cell responses [48]. In farm studies, contact with multiple animal species during pregnancy is positively correlated to Treg cell function and IFN- $\gamma$ production at birth and with innate immune receptor expression at birth and during childhood [30, 32, 48]. A failure of Th2-silencing during maturation of the immune system may underlie development of Th2mediated allergic disease [55, 57].

In conclusion, determining the optimal timing of allergy preventive interventions is critical, as early life events occurring during critical windows of immune vulnerability can have long-term impact on immune and allergy development. Increasing knowledge on the immunomodulatory effects of prenatal, perinatal and postnatal interventions, provided by studies such as the recent one by $\mathrm{D}^{\prime} \mathrm{Vaz}$ et al [26], will help to direct future strategies to combat the allergy epidemic.

\section{Acknowledgements}

The support of the Swedish Research Council, the Ekhaga Foundation, the Research Council for the South-East Sweden, the Swedish Asthma and Allergy Association, the Olle Engkvist Foundation and the Vårdal Foundation - for Health Care Sciences and Allergy Research is gratefully acknowledged.

\section{Figure legend}

The maternal dietary and microbial environment during pregnancy may program the immune development of the child via epigenetic mechanisms, regulating appropriate immune maturation. Developmental plasticity may attempt to match the responses of the offspring to the anticipated postnatal environment, but when the responses are mismatched, disease risk may increase. Possibly, immunomodulatory 
interventions that are given both pre- and postnatally may decrease the risk for mismatched responses and immune dysregulation.

\section{References}

1. Kalliomäki M, Salminen S, Arvilommi H, Kero P, Koskinen P, Isolauri E. Probiotics in primary prevention of atopic disease: a randomised placebocontrolled trial. Lancet 2001;357:1076-9.

2. Kukkonen K, Savilahti E, Haahtela T, Juntunen-Backman K, Korpela R, Poussa T, Tuure T, Kuitunen M. Probiotics and prebiotic galacto-oligosaccharides in the prevention of allergic diseases: a randomized, double-blind, placebocontrolled trial. J Allergy Clin Immunol 2007;119:192-8.

3. Abrahamsson TR, Jakobsson T, Böttcher MF, Fredrikson M, Jenmalm MC, Björkstén B, Oldaeus G. Probiotics in prevention of IgE-associated eczema: a double-blind, randomized, placebo-controlled trial. J Allergy Clin Immunol 2007;119:1174-80.

4. Taylor AL, Dunstan JA, Prescott SL. Probiotic supplementation for the first 6 months of life fails to reduce the risk of atopic dermatitis and increases the risk of allergen sensitization in high-risk children: a randomized controlled trial. J Allergy Clin Immunol 2007;119:184-91.

5. Soh SE, Aw M, Gerez I, Chong YS, Rauff M, Ng YP, Wong HB, Pai N, Lee BW, Shek LP. Probiotic supplementation in the first 6 months of life in at risk Asian infants--effects on eczema and atopic sensitization at the age of 1 year. Clin Exp Allergy 2009;39:571-8.

6. Boyle RJ, Ismail IH, Kivivuori S, Licciardi PV, Robins-Browne RM, Mah LJ, Axelrad C, Moore S, Donath S, Carlin JB, Lahtinen SJ, Tang ML. Lactobacillus GG treatment during pregnancy for the prevention of eczema: a randomized controlled trial. Allergy 2011;66:509-16.

7. Jenmalm MC. Childhood immune maturation and allergy development: regulation by maternal immunity and microbial exposure. Am J Reprod Immunol 2011;66 Suppl 1:75-80.

8. Jenmalm MC. Should more be done during pregnancy to reduce allergies in children? Clin Pract 2012;9:227-231.

9. Dunstan JA, Mori TA, Barden A, Beilin LJ, Taylor AL, Holt PG, Prescott SL. Fish oil supplementation in pregnancy modifies neonatal allergen-specific immune responses and clinical outcomes in infants at high risk of atopy: a randomized, controlled trial. J Allergy Clin Immunol 2003;112:1178-84.

10. Peat JK, Mihrshahi S, Kemp AS, Marks GB, Tovey ER, Webb K, Mellis CM, Leeder SR. Three-year outcomes of dietary fatty acid modification and house dust mite reduction in the Childhood Asthma Prevention Study. J Allergy Clin Immunol 2004;114:807-13.

11. Lauritzen L, Kjaer TM, Fruekilde MB, Michaelsen KF, Frokiaer H. Fish oil supplementation of lactating mothers affects cytokine production in $21 / 2-$ year-old children. Lipids 2005;40:669-76. 
12. Marks GB, Mihrshahi S, Kemp AS, Tovey ER, Webb K, Almqvist C, Ampon RD, Crisafulli D, Belousova EG, Mellis CM, Peat JK, Leeder SR. Prevention of asthma during the first 5 years of life: a randomized controlled trial. J Allergy Clin Immunol 2006;118:53-61.

13. Olsen SF, Osterdal ML, Salvig JD, Mortensen LM, Rytter D, Secher NJ, Henriksen TB. Fish oil intake compared with olive oil intake in late pregnancy and asthma in the offspring: 16 y of registry-based follow-up from a randomized controlled trial. Am J Clin Nutr 2008;88:167-75.

14. Furuhjelm C, Warstedt K, Larsson J, Fredriksson M, Böttcher MF, FälthMagnusson K, Duchén K. Fish oil supplementation in pregnancy and lactation may decrease the risk of infant allergy. Acta Paediatr 2009;98:1461-7.

15. Furuhjelm C, Warstedt K, Fagerås M, Fälth-Magnusson K, Larsson J, Fredriksson M, Duchén K. Allergic disease in infants up to 2 years of age in relation to plasma omega-3 fatty acids and maternal fish oil supplementation in pregnancy and lactation. Pediatr Allergy Immunol 2011;22:505-14.

16. Palmer DJ, Sullivan T, Gold MS, Prescott SL, Heddle R, Gibson RA, Makrides M. Effect of n-3 long chain polyunsaturated fatty acid supplementation in pregnancy on infants' allergies in first year of life: randomised controlled trial. BMJ 2012;344:e184.

17. Hawrylowicz C,Ryanna K. Asthma and allergy: the early beginnings. Nat Med 2010;16:274-5.

18. Renz H, Brandtzaeg P, Hornef M. The impact of perinatal immune development on mucosal homeostasis and chronic inflammation. Nat Rev Immunol 2012;12:9-23.

19. Simopoulos AP. Importance of the omega-6/omega-3 balance in health and disease: evolutionary aspects of diet. . World Rev Nutr Diet 2011;102:10-21.

20. Campbell EL, Serhan CN, Colgan SP. Antimicrobial aspects of inflammatory resolution in the mucosa: a role for proresolving mediators. Journal of immunology 2011;187:3475-81.

21. Krauss-Etschmann S, Hartl D, Rzehak P, Heinrich J, Shadid R, Del Carmen Ramirez-Tortosa M, Campoy C, Pardillo S, Schendel DJ, Decsi T, Demmelmair H, Koletzko BV. Decreased cord blood IL-4, IL-13, and CCR4 and increased TGF-beta levels after fish oil supplementation of pregnant women. J Allergy Clin Immunol 2008;121:464-470 e6.

22. Dunstan JA, Mori TA, Barden A, Beilin LJ, Taylor AL, Holt PG, Prescott SL. Maternal fish oil supplementation in pregnancy reduces interleukin-13 levels in cord blood of infants at high risk of atopy. Clin Exp Allergy 2003;33:442-8.

23. Furuhjelm C, Jenmalm MC, Fälth-Magnusson K, Duchén K. Th1 and Th2 chemokines, vaccine-induced immunity, and allergic disease in infants after maternal omega-3 fatty acid supplementation during pregnancy and lactation. Pediatric Research 2011;69:259-64.

24. Denburg JA, Hatfield HM, Cyr MM, Hayes L, Holt PG, Sehmi R, Dunstan JA, Prescott SL. Fish oil supplementation in pregnancy modifies neonatal progenitors at birth in infants at risk of atopy. Pediatr Res 2005;57:276-81.

25. Prescott SL, Barden AE, Mori TA, Dunstan JA. Maternal fish oil supplementation in pregnancy modifies neonatal leukotriene production by cord-blood-derived neutrophils. Clin Sci 2007;113:409-16. 
26. D'Vaz N, Meldrum SJ, Dunstan JA, Lee-Pullen TF, Metcalfe J, Holt BJ, Serralha M, Tulic MK, Mori TA, Prescott SL. Fish oil supplementation in early infancy modulates developing infant immune responses. Clin Exp Allergy 2012;In press.

27. Almqvist C, Garden F, Xuan W, Mihrshahi S, Leeder SR, Oddy W, Webb K, Marks GB. Omega-3 and omega- 6 fatty acid exposure from early life does not affect atopy and asthma at age 5 years. J Allergy Clin Immunol 2007;119:143844.

28. Prescott S,Nowak-Wegrzyn A. Strategies to prevent or reduce allergic disease. Ann Nutr Metabol 2011;59 Suppl 1:28-42.

29. Klemens CM, Berman DR, Mozurkewich EL. The effect of perinatal omega-3 fatty acid supplementation on inflammatory markers and allergic diseases: a systematic review. BJOG 2011;118:916-25.

30. Ege MJ, Bieli C, Frei R, van Strien RT, Riedler J, Ublagger E, Schram-Bijkerk D, Brunekreef B, van Hage M, Scheynius A, Pershagen G, Benz MR, Lauener R, von Mutius E, Braun-Fahrlander C. Prenatal farm exposure is related to the expression of receptors of the innate immunity and to atopic sensitization in school-age children. J Allergy Clin Immunol 2006;117:817-23.

31. Douwes J, Cheng S, Travier N, Cohet C, Niesink A, McKenzie J, Cunningham C, Le Gros G, von Mutius E, Pearce N. Farm exposure in utero may protect against asthma, hay fever and eczema. Eur Respir J 2008;32:603-11.

32. von Mutius E,Vercelli D. Farm living: effects on childhood asthma and allergy. Nat Rev Immunol 2010;10:861-8.

33. Conrad ML, Ferstl R, Teich R, Brand S, Blumer N, Yildirim AO, Patrascan CC, Hanuszkiewicz A, Akira S, Wagner H, Holst O, von Mutius E, Pfefferle PI, Kirschning CJ, Garn H, Renz H. Maternal TLR signaling is required for prenatal asthma protection by the nonpathogenic microbe Acinetobacter lwoffii F78. J Exp Med 2009;206:2869-77.

34. Cao L, Wang J, Zhu Y, Tseu I, Post M. Maternal endotoxin exposure attenuates allergic airway disease in infant rats. Am J Physiol Lung Cell Mol Physiol 2010;298:L670-7.

35. Duchén K, Casas R, Fagerås-Böttcher M, Yu G, Björkstén B. Human milk polyunsaturated long-chain fatty acids and secretory immunoglobulin A antibodies and early childhood allergy. Pediatr Allergy Immunol 2000;11:2939.

36. Mihrshahi S, Peat JK, Webb K, Oddy W, Marks GB, Mellis CM. Effect of omega-3 fatty acid concentrations in plasma on symptoms of asthma at 18 months of age. Pediatr Allergy Immunol 2004;15:517-22.

37. Mihrshahi S, Peat JK, Marks GB, Mellis CM, Tovey ER, Webb K, Britton WJ, Leeder SR. Eighteen-month outcomes of house dust mite avoidance and dietary fatty acid modification in the Childhood Asthma Prevention Study (CAPS). J Allergy Clin Immunol 2003;111:162-8.

38. Johansson S, Wold AE, Sandberg AS. Low breast milk levels of long-chain n-3 fatty acids in allergic women, despite frequent fish intake. Clin Exp Allergy 2011;41:505-15.

39. Dugoua JJ, Machado M, Zhu X, Chen X, Koren G, Einarson TR. Probiotic safety in pregnancy: a systematic rewiew and meta-analysis of randomized 
controlled trials of Lactobacillus, Bifidobacterium and Saccharomyces spp. J Obstet Gynaecol Can 2009;31:542 - 552.

40. Koletzko B, et al. The roles of long-chain polyunsaturated fatty acids in pregnancy, lactation and infancy: review of current knowledge and consensus recommendations. J Perinat Med 2008;36:5-14.

41. Imhoff-Kunsch B, Briggs V, Goldenberg T, Ramakrishnan U. Effect of n-3 Long-chain Polyunsaturated Fatty Acid Intake during Pregnancy on Maternal, Infant, and Child Health Outcomes: A Systematic Review. Paediatr Perinat Epidemiol 2012;26 Suppl 1:91-107.

42. Kim JK, Samaranayake M, Pradhan S. Epigenetic mechanisms in mammals. Cell Mol Life Sci 2009;66:596-612.

43. Wadhwa PD, Buss C, Entringer S, Swanson JM. Developmental origins of health and disease: brief history of the approach and current focus on epigenetic mechanisms. Semin Reprod Med 2009;27:358-68.

44. Barker DJ. The fetal and infant origins of adult disease. BMJ 1990;301:1111.

45. Godfrey KM, Lillycrop KA, Burdge GC, Gluckman PD, Hanson MA. Epigenetic mechanisms and the mismatch concept of the developmental origins of health and disease. Pediatr Res 2007;61:5R-10R.

46. Böttcher MF, Jenmalm MC, Voor T, Julge K, Holt PG, Björkstén B. Cytokine responses to allergens during the first 2 years of life in Estonian and Swedish children. Clin Exp Allergy 2006;36:619-28.

47. Vuillermin PJ, Ponsonby AL, Saffery R, Tang ML, Ellis JA, Sly P, Holt P. Microbial exposure, interferon gamma gene demethylation in naive T-cells, and the risk of allergic disease. Allergy 2009;64:348-53.

48. Schaub B, Liu J, Hoppler S, Schleich I, Huehn J, Olek S, Wieczorek G, Illi S, von Mutius E. Maternal farm exposure modulates neonatal immune mechanisms through regulatory T cells. J Allergy Clin Immunol 2009;123:77482.

49. Janson PC, Linton LB, Bergman EA, Marits P, Eberhardson M, Piehl F, Malmström V, Winqvist O. Profiling of CD4+ T cells with epigenetic immune lineage analysis. J Immunol 2011;186:92-102.

50. Brand S, Teich R, Dicke T, Harb H, Yildirim AO, Tost J, Schneider-Stock R, Waterland RA, Bauer UM, von Mutius E, Garn H, Pfefferle PI, Renz H. Epigenetic regulation in murine offspring as a novel mechanism for transmaternal asthma protection induced by microbes. J Allergy Clin Immunol 2011;128:618-25 e1-7.

51. Abelius MS, Ernerudh J, Berg G, Matthiesen L, Nilsson LJ, Jenmalm MC. High cord blood levels of the T-helper 2-associated chemokines CCL17 and CCL22 precede allergy development during the first 6 years of life. Pediatr Res 2011;70:495-500.

52. Sandberg M, Frykman A, Jonsson Y, Persson M, Ernerudh J, Berg G, Matthiesen L, Ekerfelt C, Jenmalm MC. Total and allergen-specific IgE levels during and after pregnancy in relation to maternal allergy. J Reprod Immunol 2009;81:82-8.

53. Lim RH, Kobzik L, Dahl M. Risk for asthma in offspring of asthmatic mothers versus fathers: a meta-analysis. PloS One 2010;5:e10134.

54. Kim HY, DeKruyff RH, Umetsu DT. The many paths to asthma: phenotype shaped by innate and adaptive immunity. Nat Immunol 2010;11:577-84. 
55. Abrahamsson TR, Sandberg Abelius M, Forsberg A, Björkstén B, Jenmalm MC. A Th1/Th2-associated chemokine imbalance during infancy in children developing eczema, wheeze and sensitization. Clin Exp Allergy 2011;41:172939.

56. Sandberg M, Frykman A, Ernerudh J, Berg G, Matthiesen L, Ekerfelt C, Nilsson LJ, Jenmalm MC. Cord blood cytokines and chemokines and development of allergic disease. Pediatr Allergy Immunol 2009;20:519-27.

57. Böttcher MF, Jenmalm MC, Björkstén B. Immune responses to birch in young children during their first 7 years of life. Clin Exp Allergy 2002;32:1690-8. 


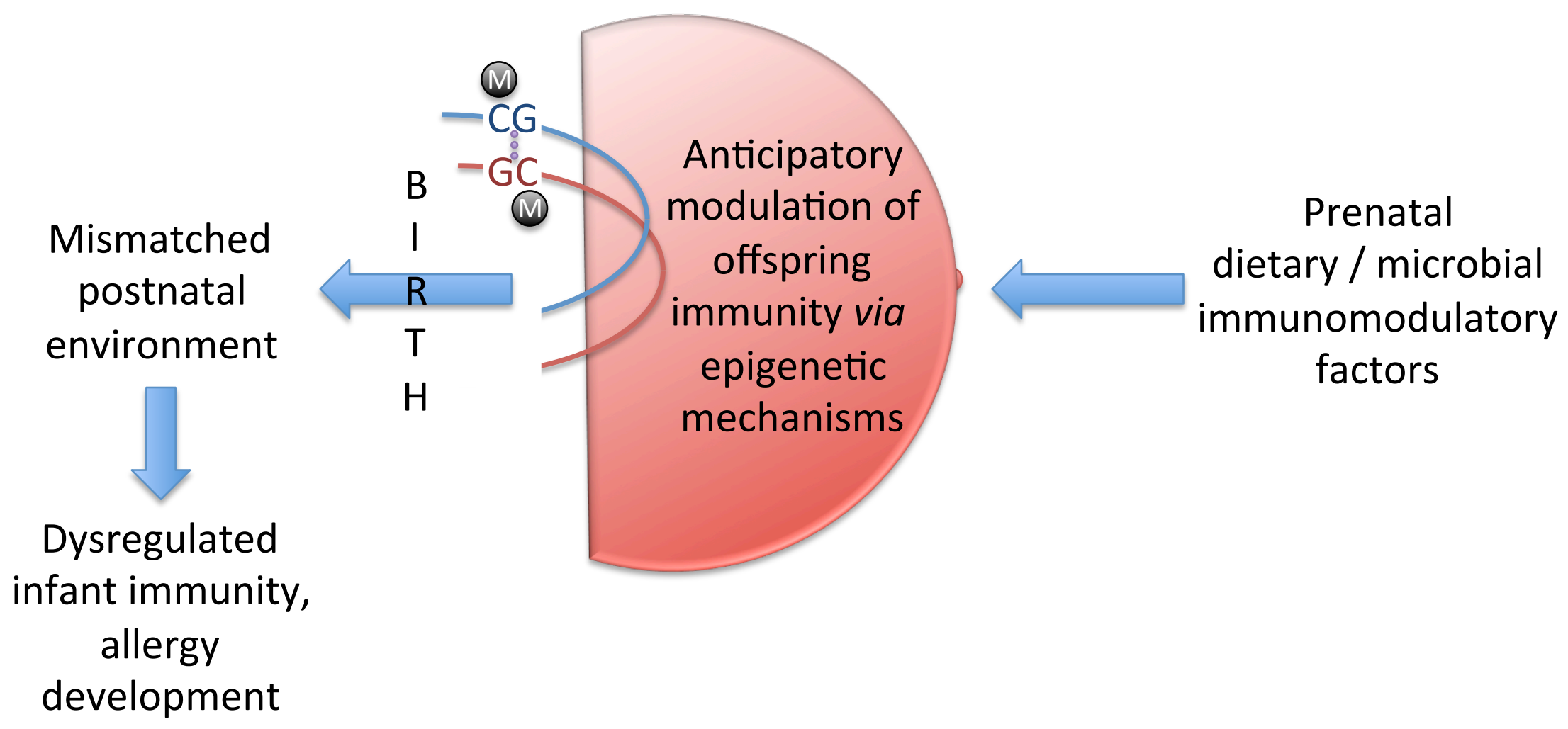

